\title{
Effects of Process Parameters on MRR, EWR and Ra in Nanoparticles Mixed EDM
}

\author{
R Boopathi ${ }^{1 *}$, R Thanigaivelan ${ }^{1}$ and $\mathbf{M}$ Prabu $^{2}$ \\ ${ }^{1}$ Department of Mechanical Engineering, India \\ ${ }^{2}$ Department of Mechanical Engineering, India \\ *Corresponding author: R Boopathi, Department of Mechanical Engineering, Mallasamudram, India \\ Submission: 沘 February 23, 2018; Published: 監 March 09, 2018
}

\begin{abstract}
Electrical discharge machining characteristics of inconel 718 alloy using titanium carbide (TiC) nanoparticles mixed dielectric fluid was studied. Experiments have been performed according to face centered central composite design. The effect of input parameters such as current, pulse on-time and pulse off-time on the output responses like material removal rate (MRR), tool wear rate (TWR) and surface roughness (Ra) are evaluated. Dielectric fluid used in this experiment was kerosene mixed with TiC nanoparticles. The result shows that MRR and Ra gets improved, TWR get reduced.
\end{abstract}

Keywords: TiC; EDM; MRR; TWR; Ra

\section{Introduction}

EDM process is a nonconventional machining method, where electrical energy is used to generate electrical spark and material removal occurs mainly due to thermal energy of the spark. In EDM machining, the two metals part which are submerged in an insulating liquid are allied to a cause of current and are switched on and off automatically depending upon the parameters set on the execute. The new idea of manufacturing uses nonconventional energy sources like sound, light, chemical, mechanical, electrons, electrical and ions [1]. EDM is one of the most popular process and has became a basic machining method for the manufacturing industries of aerospace, nuclear engineering, micro nozzle fabrication, aerospace, heat resistance material, surgical components, drilling of composites, automotive and die-mold production [2]. New advancement in the field of material science have lead to development of hard materials, composite materials, good mechanical properties, thermal characteristics as well as sufficient electrical conductivity that can readily be machined by spark erosion [3]. Powder mixed dielectric fluid in electrical discharge machining is a most recent advanced material removal process to develop the machining efficiency and surface finish. Powder particles mixed is a dielectric medium leads to a faster sparking and increased thermal conductivity within a discharge, causing quicker erosion from the workpiece surface and increases the MRR [4]. Gunawan et al. [5] investigated the addition of nanoparticles to a dielectric fluid also improves the surface quality by reducing the tool wear rate. Have been studied powder mixed EDM performance under roughing discharge parameters in order to increase the MRR and decrease the TWR. Inconel 718 is a high strength, temperature resistant nickel based super alloy. Inconel 718 is hard to machine, because of its poor thermal properties, high toughness, high hardness, high work hardened rate [6]. Hence a challenge has been made to investigate the effects of EDM of inconel 718 alloy in this work. From the literature it is found that that no extensive work is reported on EDM of Inconel 718 alloy with titanium carbide nanoparticles mixed in dielectric. Hence, in this work to study the effect of machining parameters of inconel 718.

\section{Experimental Setup}

Experiments have been conducted in Electronica die sinking EDM machine. Commercial grade kerosene was used as dielectric fluid mixed with titanium carbide nanoparticles. The brass electrode with $6 \mathrm{~mm}$ diameter act as cathode and Inconel 718 was considered as anode. In the present study, three factor three level central composite rotatable designs was selected for conducting the experiments. The input parameters and their levels taking by into account the whole range of the machining capability. Machining time for all the experiments was kept constant as $5 \mathrm{~min}$. The MRR and TWR were calculated from the difference between the final weight and initial weight of the sample. The Ra is measured using a talysurf tester.

\section{Results and Discussion}

The influence of the input process parameters like current, pulse on-time and pulse off-time on the process responses, such as MRR, TWR, and Ra were analyzed. From Figure 1 it is observed that 
with an increase in current, the value of MRR increases linearly and then increases suddenly, TWR increases linearly. It is due increasing current increases the pulsation energy that the material is removed more easily. The Figure 2 shows that maximum MRR was obtained when the value of pulse on-time is $200 \mu \mathrm{s}$. With the increase in pulse on-time from $500 \mu$ s to $1000 \mu \mathrm{s}$, the MRR again gets increased. This may be due to reason that with high pulse on-time more material gets melted at the tool work piece interface.

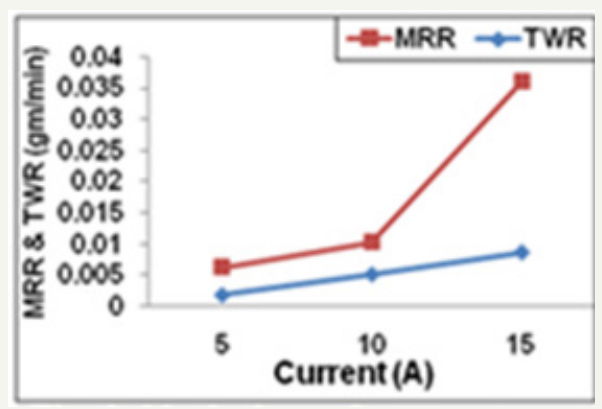

Figure 1 : Variation of current with MRR and TWR.

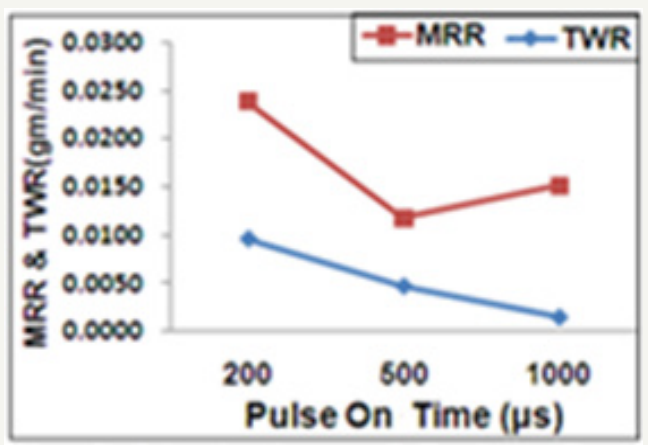

Figure 2 : Variation of pulse on time with MRR and TWR.

It is observed from the figure that with the increase in pulse on-time, TWR gets decreased. In Figure 3 the effect of pulse offtime on MRR and TWR is given with the increase in pulse off-time from $200 \mu$ s to $500 \mu$ s the MRR gets decreased. At short pulse offtime of $500 \mu \mathrm{s}$, MRR is lesser due to the reality that with short pulse off-time the possibility of arcing is very high. This is because the dielectric gap between the work piece and tool cannot be flushed out correctly and the waste particles remained in the discharge gap results, in reducing the value of MRR. It was found from the figure that increase of pulse off time, decreases the TWR.

The relations between the current and Ra is shown in Figure 4. Ra increases with increase in current, upto 5amps and then decreases after 10amps. This is due to TiC nanoparticles extend the discharge passage and facilitates easy evacuation of debris in the spark gap. Morever over powder particles led to regular spreading of discharge energy in all directions. Figure 5 depicts the influence of pulse on-time on Ra. Increase in pulse on-time, Ra gets increased up to $500 \mu \mathrm{s}$ and then starts decreasing slightly up to pulse on-time $1000 \mu \mathrm{s}$. Figure 6 presents the relationship between the pulse offtime and Ra. The value of Ra linearly increases with the increase of pulse off-time and with further increase of pulse off-time, Ra gets decreased.

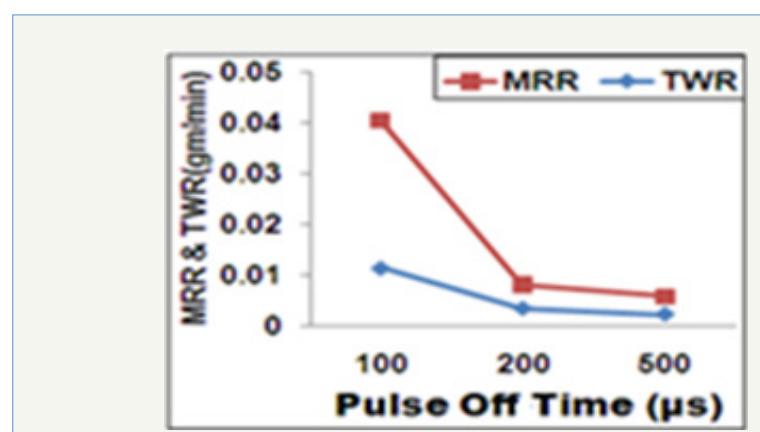

Figure 3 : Variation of pulse off time with MRR and TWR.

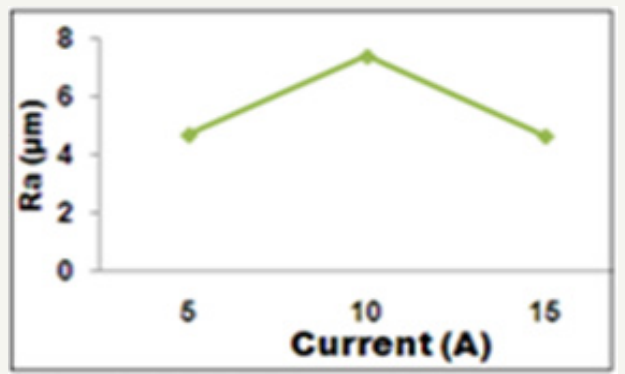

Figure 4 : Variation of current with Ra.

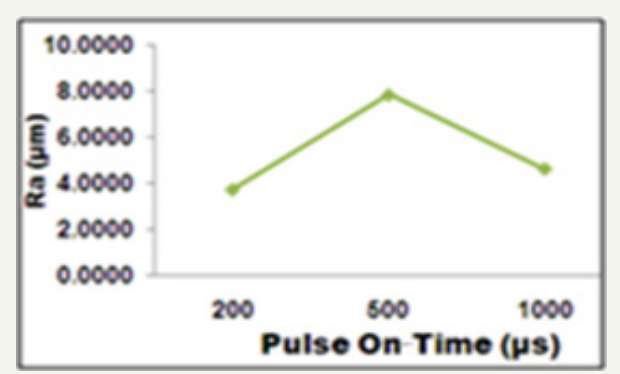

Figure 5 : Variation of pulse on time with Ra.

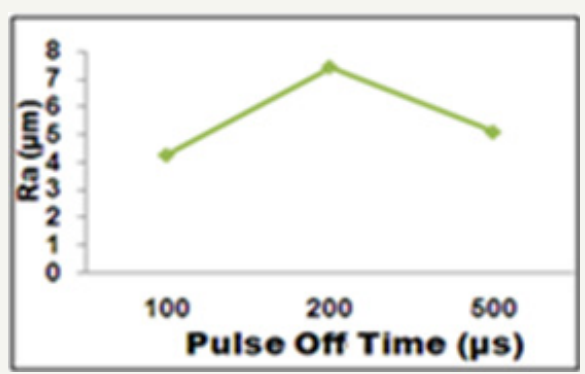

Figure 6 : Variation of pulse off time with Ra.

\section{Conclusion}

TiC nanoparticles are mixed into the dielectric fluid of EDM and an enhanced rate of MRR and lower Ra has been achieved. MRR be improved with increase in current. TWR slightly increase by increasing the current. The MRR decreased with increase in pulse on-time and in case of TWR it gets decreased. For all parameters lower and higher levels Ra is improved. From the result, it was 
concluded that, current affects the MRR, TWR and Ra rather than other parameters.

The TiC nanoparticles suspended dielectric significantly improves the MRR and Ra simultaneously. On comparing electrodes, vibrating electrode results in increases in MRR and Ra value. Based on the conducted experiments the current and pulse on-time have a significant influence on MRR with vibrating electrodes. Ra is found to be lower for non-vibrating electrodes and pulse off-time shows a significant influence on the surface quality.

The vibrating electrodes have the major impact on MRR and Ra for all machining conditions. It is observed that the use of brass and copper vibrating electrodes increases in MRR, and the TiC mixed dielectric fluid improves quality of surface finish.

\section{References}

1. Sandeep K (2013) Current research trends in electrical discharge machining. Res J Eng Sci 2(2): 56-60.
2. Singh H, Singh A (2012) Examination of surface roughness using different machining parameter in EDM. Int J Modern Eng Res 2(6): 4478-4479.

3. Kumar N, Kumar L, Tewatia H, Yadav R (2012) Comparative study for MRR on die-sinking EDM using electrode of copper \& graphite. Int J Adv Tech \& Eng Res 2(2): 170-174.

4. Kuldeep 0, Garg RK, Singh KK (2011) Experimental investigation and modeling of PMEDM process with chromium powder suspended dielectric. Int J Appl Sci Eng 9(2): 65-81.

5. Prihandana GS, Mahardika M, Hamdi M, Wong YS, Mitsui K (2011) Accuracy improvement in nanographite powder-suspended dielectric fluid for micro-electrical discharge machining processes. Int J Adv Manuf Tech 56(1-4): 143-149.

6. Sudhakara D, Venkataramana BN, Sreenivasulu B (2012) The experimental analysis of surface characteristics of inconel-718 using electrical discharge machining. Int J Mech Eng \& Rob Res 1(3): 371-388.
Creative Commons Attribution 4.0

International License

For possible submissions Click Here

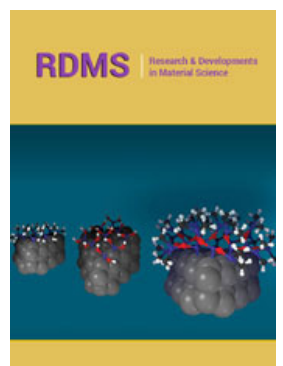

\section{Research \& Development in Material Science}

\section{Benefits of Publishing with us}

- High-level peer review and editorial services

- Freely accessible online immediately upon publication

- Authors retain the copyright to their work

- Licensing it under a Creative Commons license

- Visibility through different online platforms 